\title{
Auto-hemoterapia como adjuvante no tratamento de mastocitoma em cão: relato de caso
}

\section{Autohemotherapy as adjuvant in the treatment of mastocytoma in a dog: case report}

\author{
Ana Maria Quessada, ${ }^{\star}$ Ciro José Sousa de Carvalho, ${ }^{* *}$ Rafael Norberto de Oliveira, ${ }^{\star * *}$ Paulo Marques Costa, ${ }^{* * \star *}$ \\ Sammya Roberta de Vasconcelos Barbosa, ${ }^{* * *}$ Silvana Maria Medeiros de Sousa e Silva*
}

\begin{abstract}
Resumo
Este trabalho tem como objetivo relatar o uso de terapia neoadjuvante (auto-hemoterapia) no tratamento de um caso de mastocitoma canino. O tratamento desta neoplasia pode ser cirúrgico, quimioterápico ou com a associação destes dois métodos. A auto-hemoterapia (AHT) é utilizada com sucesso no tratamento de algumas enfermidades em animais. O cão do presente relato foi diagnosticado com mastocitoma e submetido a tratamento com AHT (10 ml de sangue, via intramuscular retirados da jugular), associado a tratamento cirúrgico. O uso dessa terapia possibilitou prolongar a sobrevivência do animal com qualidade de vida e satisfação do proprietário.
\end{abstract}

Palavras-chave: canino, mastocitoma, tratamento, auto-hemoterapia.

\begin{abstract}
This paper aims to report the use of autohemotherapy as an aid in treating a case of canine mast cell tumor. Treatment of this type of tumour can be surgical, chemotherapy and combination of these two methods. The autohemotherapy is a technique used successfully in the treatment of some diseases in animals. The dog of this report was diagnosed with mast cell tumor and underwent treatment with autohemotherapy $(10 \mathrm{ml}$ of blood withdrawn from jugular intramuscularly) associated with surgical treatment. The use of this therapy allowed to prolong the animal's survival with quality of life and owner satisfaction.
\end{abstract}

Keywords: canine, mastocytoma, treatment, autohemotherapy.

\section{Introdução}

O mastocitoma é uma neoplasia cutânea maligna de mastócitos (Souza et al., 2006), sendo o segundo tumor mais comum no cão. Nos caninos, aparecem mais frequentemente nos membros, abdômen, tórax e cabeça (Souza et al., 2006; Ferreira et al., 2008; Torres Neto, 2008). O diagnóstico do mastocitoma é realizado por exame citológico (Pires et al., 2007; Rosseto et al., 2009) e/ou histopatológico (Costacasagrande et al., 2008; Ferreira et al., 2008; Furlani et al., 2008). No tratamento usa-se excisão cirúrgica (Costacasa-grande et al., 2008), quimioterapia e associação dos dois métodos (Costacasa-grande et al., 2008; Furlani et al., 2008).

A auto-hemoterapia é uma técnica usada com sucesso no tratamento de papilomatose canina (Cesarino et al. 2008) e bovina (Silva et al. 2004), provavelmente pelo aumento da imunidade orgânica (Paradysz et al., 1998). A técnica possibi- litou redução de massas neoplásicas em cães (Drumond, 2009).

\section{Relato do caso}

Com queixa de nódulos pelo corpo, foi atendido no Hospital Veterinário da Universidade Federal do Piauí um cão macho, sem raça definida, seis anos de idade, $28 \mathrm{~kg}$, apresentando várias massas tumorais cutâneas, localizadas: na pálpebra superior direita (Figura 1a), no prepúcio I (Figura 1b), na bolsa escrotal (Figura 1c), na região abdominal lateral e membros pélvicos.

O hemograma e o exame radiológico não apresentaram anormalidades. Solicitou-se exame citológico cuja conclusão foi mastocitoma grau I. O exame revelou células bem diferenciadas, com granulações evidentes, havia anisocitose discreta e ausência de mitoses (Figura 2). Como as massas

\footnotetext{
* Departamento de clínica e cirurgia veterinária, Centro de Ciências Agrárias (CCA), Universidade Federal do Piauí (UFPI), Campus Universitário, 64.049-550, Teresina, PI. A quem enviar a correspondência: E-mail: quessadavet@gmail.com.

** Pós-graduação em Ciência Animal, UFPI, Campus Universitário, 64.049-550, Teresina, PI.

*** Autônomo. Teresina, PI.

${ }^{* * * *}$ Hospital Veterinário Universitário, CCA, UFPI, Campus Universitário, 64.049-550, Teresina, PI.
} 

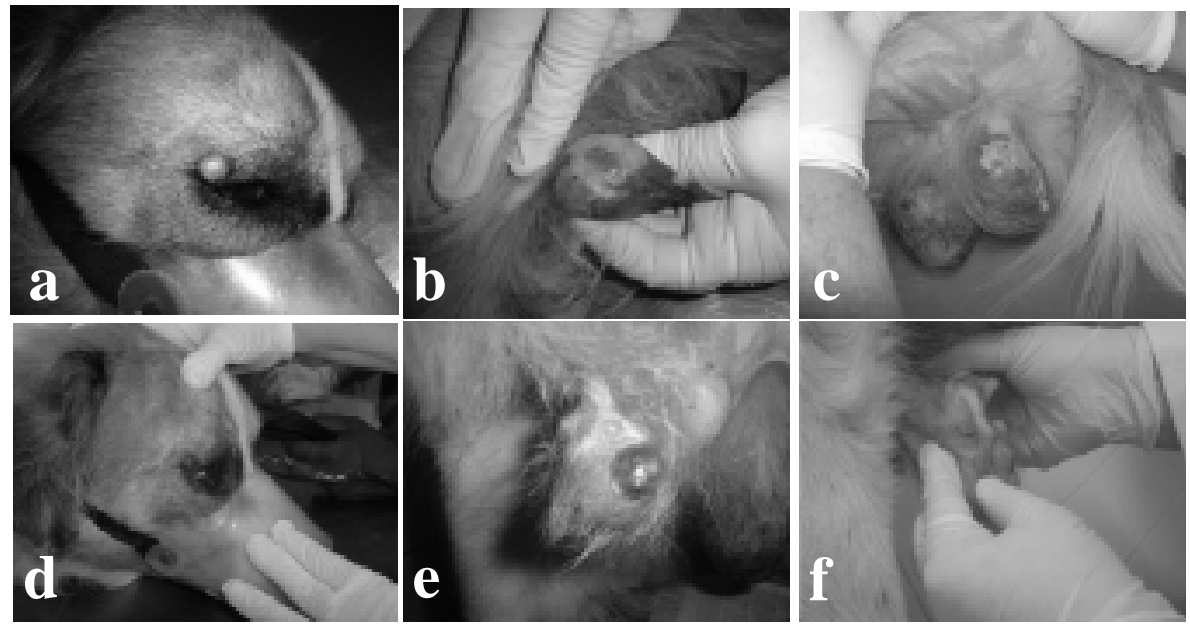

Figura 1: Cão macho, SRD, seis anos, portador de mastocitoma. Antes das sessões de autohemoterapia observou-se: a) nódulo na pálpebra superior direita, b) massas tumorais na região prepucial, c) massa tumoral na bolsa escrotal. Após uma semana de tratamento com autohemoterapia: d) redução do nódulo na região palpebral, e) redução das massas no prepúcio, f) redução da massa do escroto

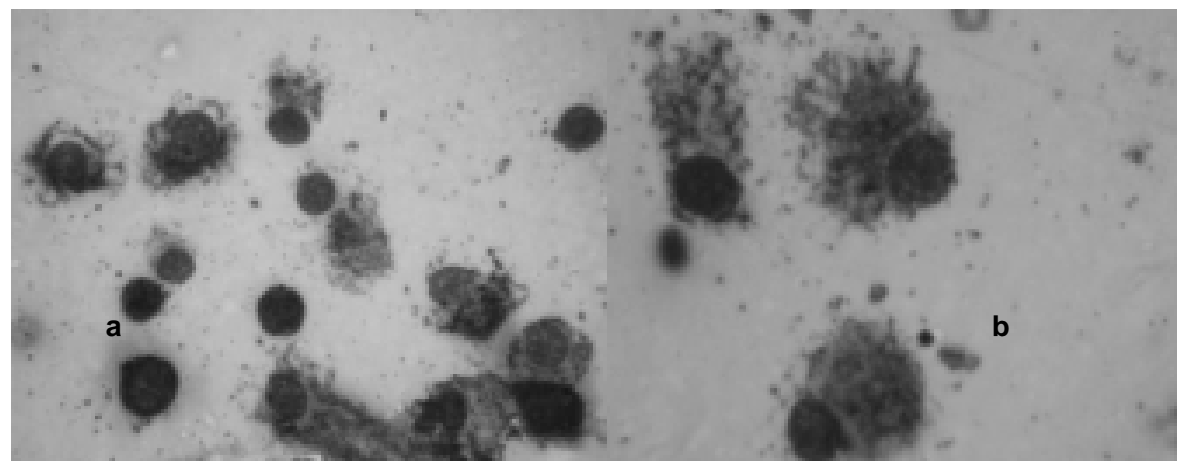

Figura 2: Fotomicrografia de análise citológica de mastocitoma, a) observa-se presença de moderada quantidade de mastócitos altamente em degranulação - Gienmsa. 40x. b) mastócitos altamente granulados- Giemnsa 100x de $26,15 \%$ (Costa-casagrande et al., 2008), 36,37\% (Furlani et al., 2008) e 42,86\%) (Pires et al., 2007). No entanto, discute-se a possibilidade destes animais serem mais frequentes nos atendimentos (Ferreira et al., 2008), como acontece no serviço onde o animal foi atendido.

A maior proporção de cães que apresentam mastocitoma está entre 8 e 9 anos (Ferreira et al., 2008; Furlani et al., 2008; Pinczowski, 2008), porém, animais jovens podem ser afetados (Pinczowski, 2008), como o cão deste relato.

Em relação ao sexo, estudos brasileiros são contraditórios, apontando frequência maior em fêmeas (Ferreira et al., 2008) e em machos (Pires et al., 2007). O caso em questão ocorreu em um macho.

Embora as massas solitárias sejam mais comuns (Torres Neto, 2008), este cão apresentou múltiplas massas, o que pode piorar o prognóstico (Furlani et al., 2008). A localização das massas observadas no caso, nódulo na região da cabeça (pálpebra), massas na região do prepúcio e escroto, é citada com frequência pela maioria dos autores (Souza et al., 2006; Ferreira et al., 2008; Torres Neto, 2008).

O exame citológico, utilizado neste caso (Figura 2) é suficiente para diagnosticar este tipo de neoplasia foram consideradas inoperáveis, iniciou-se AHT, a qual foi realizada semanalmente, injetando-se nos músculos glúteos $10 \mathrm{ml}$ de sangue (sem anticoagulante), retirados da jugular. A injeção foi feita imediatamente após a retirada. Após a primeira aplicação, já se observou redução das massas (Figura 1d e 1e) e cicatrização da úlcera escrotal (Figura 1f). Depois de seis sessões semanais de AHT, várias massas tumorais regrediram significativamente de tamanho e algumas desapareceram completamente. Após estas seis aplicações de AHT, o proprietário abandonou o tratamento, mas retornou um mês após porque o animal piorou. O cão foi submetido a ablação da bolsa escrotal e retirada de duas massas muito grandes (uma na região abdominal lateral e outra no membro pélvico esquerdo). O animal se recuperou bem no pós-operatório e as sessões semanais de AHT foram retomadas até os dias atuais. Desde o diagnóstico até o relato já se passaram cinco meses.

\section{Discussão e conclusão}

Como no caso do animal apresentado, a maioria dos trabalhos consultados refere os cães sem raça definida como os mais afetados pelo mastocitoma, com frequências
(Pires et al., 2007; Rosseto et al., 2009) e também para graduar o tumor (Furlani et al., 2008; Torres Neto, 2008).

Embora o tratamento cirúrgico seja recomendado por ser curativo (Furlani et al., 2008), no caso em questão, a cirurgia não foi realizada no primeiro atendimento devido à grande quantidade de massas e à baixa malignidade. Além disso, a necessidade de se retirar margens de segurança amplas (Thamm e Vail, 2007) tornou inviável o procedimento cirúrgico imediato. A retirada das massas prepuciais (Figura 1e) com as margens necessárias provavelmente produziriam exposição peniana, exigindo penectomia e uretrostomia. A retirada da massa palpebral (1c) com as margens de segurança recomendadas provocaria exposição do globo ocular e possível enucleação. Desta forma, optou-se por um tratamento alternativo que possibilitasse a redução das massas (Drumond, 2009). Para embasar esta decisão podese citar que há necessidade de obtenção de maiores informações sobre o tumor e efetividade dos diferentes tratamentos no território nacional (Costa-casagrande et al., 2008).

A quimioterapia, também indicada em mastocitomas (Costacasa-grande et al., 2008; Furlani et al., 2008) poderia 
ser utilizada neste animal. No entanto, no primeiro momento, optou-se por não usar medicamentos para que se pudesse observar o efeito da AHT sem interferências.

A opção pela AHT se deu em razão dos resultados favoráveis desta terapia em outros tipos de neoplasias em animais (Silva et al., 2004; Cesarino et al., 2008; Drumond, 2009). Uma semana após a primeira aplicação (na segunda aplicação), observou-se que a úlcera do escroto cicatrizou (Figura 1b), a massa palpebral apresentou redução (Figura 1d) assim como as do prepúcio (Figura 1f).

Provavelmente a AHT funcionou como um estimulante imunológico (Paradysz et al., 1998).

Atualmente (desde o diagnóstico até os dias atuais se passaram cinco meses), o cão está clinicamente bem (Figura 3), tendo sido realizada a sexta sessão de auto-hemoterapia (com intervalos semanais) após a cirurgia. Algumas massas tumorais permanecem, mas estão pequenas e não causam alterações patológicas sistêmicas. $\mathrm{O}$ animal tem boa qualidade de vida e o proprietário está satisfeito com os resultados.

Considera-se que o tratamento com auto-hemoterapia auxiliou sobremaneira na sobrevivência do animal. Ressaltese o fato de que animais com múltiplas massas como este cão têm prognóstico desfavorável com baixa sobrevida. (Furlani et al., 2008).

\section{Referências}

CESARINO M., ÁVILA D.F., FERNANDES C.C., SILVA C.B., SCHERER D.L., DIAS T.A.; MENDONÇA C.S., CASTRO J.R. Efeito da autohemoterapia associada com clorabutanol no tratamento da papilomatose oral em cão (Canis familiaris) - Relato de caso. In: SEMANA CIENTÍFICA DE MEDICINA VETERINÁRIA DE UBERLÂNDIA, 20., 2008, Uberlândia. Resumos...Uberlândia: Universidade Federal de Uberlândia, p. 62. Disponível em: http://www.famev.ufu.br/ documentos/anais_secivet_2008.pdf. Acesso em 20 dez 2008.

COSTA-CASAGRANDE, T.A.; ELIAS, D.S.; MELO, S.R.; MATERA, J.M. Estudo retrospectivo do mastocitoma canino no serviço de cirurgia de pequenos animais - Hospital Veterinário da Faculdade de Medicina Veterinária e Zootecnia da Universidade de São Paulo. Archives of Veterinary Science, v. 13, n. 3, p. 176-183, 2008. Disponível em: <http://ojs.c3sl.ufpr.br/ojs2/index.php/veterinary/article/viewFile/ 11667/9797>. Acesso em 02 set. 2009.

DRUMOND, K.O. Auto-hemoterapia, vincristina e associação dos dois tratamentos no tumor venéreo transmissível canino. 2009. 82 p. Dissertação (Mestrado em Ciência Animal)-Programa de Pós-Graduação em Ciência Animal, Universidade Federal do Piauí, Teresina, 2009. FERREIRA, K.C.R.S.; OLIVEIRA, L.O.; OLIVEIRA R.T.; GOMES, C.; TOURRUCÔO, A.C.;FARAON, A.; CARDOSO, C.S.; FERNANDES, A.O.; GARCEZ, T.N.A.; COELHO, A.J.A. Estudo retrospectivo de cães acometidos por mastocitoma cutâneo atendidos pelo serviço de oncologia veterinária do Hospital de Clínicas Veterinárias da Universidade Federal do Rio Grande do Sul no período de maio de 2004 a junho de 2008. In: CONGRESSO BRASILEIRO DE MEDICINA VETERINÁRIA, Gramado, 35., 2008. Disponível em: <http://www. sovergs.com.br/conbravet2008/anais/cd/resumos/R0672-1.pdf.> Acesso em 22 set. 2009.

FURLANI, J. M.; DALECK, C.R.; VICENTI, F.A.M.; DE NARDI, A.B.; PEREIRA, G.T.; SANTANA, A.E.; EURIDES, D.; SILVA, L.A.F. Mastocitoma Canino: Estudo Retrospectivo. Ciência Animal Brasileira. v. 9, n. 1, p. 242-250, 2008. Disponível em: <http://www.revistas.ufg.br /index.php/vet/article/viewFile/1060/3453>. Acesso em 12 set. 2009. PARADYSZ A, FRYCZKOWSKI M, KRAUZE-BALWIÑSKA Z, GAJEWSKI D. Studies on the behavior of some immunologic
A auto-hemoterapia pode ser recomendada como auxiliar no tratamento de neoplasias em cães.

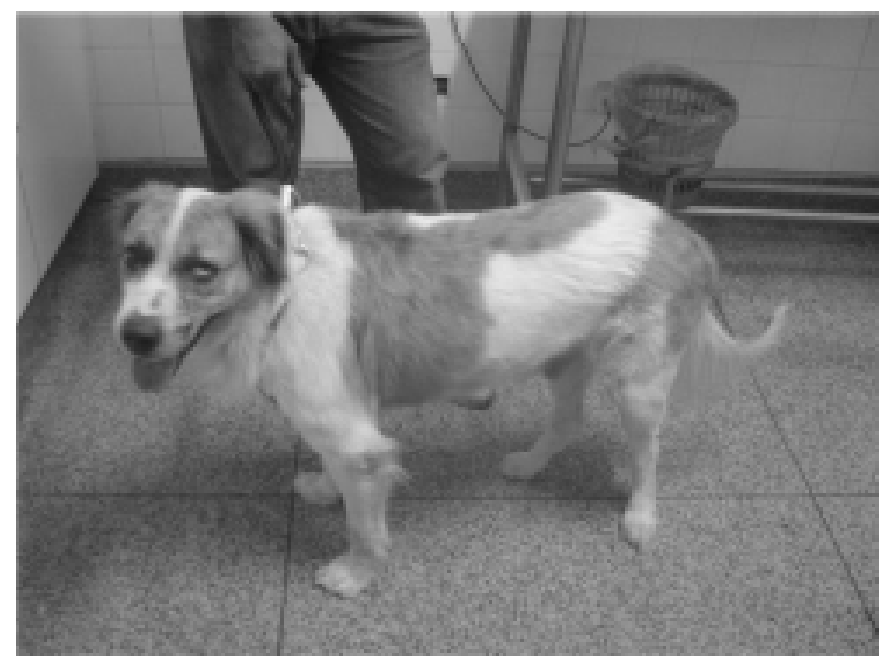

Figura 3: cão macho, SRD, 6 anos de idade, portador de mastocitoma, após 70 dias de tratamento com auto-hemoterapia associada ao tratamento cirúrgico

parameters after local, endoscopic autohemotherapy in children treated for vesicoureteral reflux. Wiadomoœci lekarskie, v. 51, suppl 3, p. 114-119, 1998. (Abstract). Disponível:<http://www.ncbi. nlm.nih.gov/pubmed/9814119?itool=EntrezSystem2.PEntrez. Pubmed.Pubmed_ResultsPanel.Pubmed_RVDocSum\&ordinalpos=30>. Acesso em 10 out. 2009.

PINCZOWSKI, P. Mastocitoma canino: abordagem histopatológica e imunoistoquímica na busca de biomarcadores prognósticos. Dissertação de mestrado. Faculdade de Medicina Veterinária e Zootecnia, Universidade Estadual Paulista "Julio de Mesquita Filho", Campus Botucatu, 2008. Disponível em: http://www.dominiopublico. gov.br/download/texto/cp048916.pdf. Acesso em 18 out. 2009.

PIRES, L.V.; CARVALHO, C. J. S.; SILVA L. S.; GOMES, L. A.; SOUSA JUNIOR, A.; GOMES, C. M.; COSTA, F.A. L.;SILVA, S. M. M. S. Mastocitoma em cães. In: CONGRESSOBRASILEIRODE MEDICINA VETERINÁRIA, Santos, 34., 2007. Disponível em: <http://www. spmv.org.br/conbravet 2007/dados/trabalhos/caesegatos/161.doc>. Acesso em 07 jan. 2009. ROSSETTO, V.J.V.; MORENO, K.; GROTTI. C.B.; REIS, A.C.F.; BRACARENSE, A.P.F.R.L. Frequência de neoplasmas em cães diagnosticados por exame citológico: estudo retrospectivo em um hospital-escola. Semina: Ciências Agrárias, v. 30, n. 1, p. 189-200, 2009. Disponível em: <http://www.uel.br/revistas/uel/index.php/ semagrarias/article/viewFile/2662/2314>. Acesso em 13 dez. 2009. SILVA, L.A.F.; VERÍSSIMO, A.C.C.; VIANA FILHO, P.R.L.; FIORAVANTI M.C.S.; LINHARES, D.; FONTGALLAND, G.C.; ROMANI, A.F.;TRINDAD,E B.R.. Eficiência da repetição de diferentes protocolos de tratamentos para papilomatose bovina. Revista da Faculdade de Zootecnia, Veterinária e Agronomia, v. 11, n. 1, p. 153-165, 2004.

SOUZA, T.M.; FIGUERA, R.A.;IRIGOYEN, L.F.; BARROS, C.S.L. Estudo retrospectivo de 761 tumores cutâneos em cães. Ciência Rural. v. 36, n. 2, p. 555-560, 2006. Disponível em: <http://www.scielo.br/pdf/ cr/v36n2/a30v36n2.pdf >. Acesso em 23 out. 2009.

TORRES NETO, R.; VIDALE, M.M.; RAHAL, S.C.; AMORIM, R.L. Avaliação do índice mitótico e número de células bi e multinucleadas dos mastocitomas cutâneos caninos no exame citopatológico. Veterinária e Zootecnia. supl. ao v. 15, n. 3, p. 25-28, 2008. Disponível em: <http://www.fmvz.unesp.br/revista/volumes/vol15_n3_supl/ Suplemento_v15_n3.pdf>. Acesso em 10 set. 2009. 